\title{
DER GEIST VON TIMMENDORF
}

\section{Liebe Kolleginnen, liebe Kollegen!}

AKUPUNKTURKONGRESS TIMMENDORF | Der diesjährige Kongress in Timmendorf zum Funktionskreis Herz/Dünndarm war ein Highlight in diesem Jahr. An die 180 Teilnehmer waren eine Woche lang versammelt, um aktuelle Informationen aus der aurikulomedizinischen Forschung zu erhalten. Viele verschiedenste WorkshopAngebote wurden begeistert angenommen und in der veranstaltungsfreien Zeit wurde weiterer kollegialer Austausch gepflegt. Es war außerdem eine Freude, den Verjüngungsprozess des Publikums bemerken zu dürfen. In den generationsübergreifenden Gesprächen konnten viele ihr persönliches Netzwerk erweitern. Wie durch ein Wunder fanden sich schon in diesem Jahr einige musikbegeisterte Kollegen zu abendlichen Proben zusammen. Unter Anleitung des Dirigenten, Konzertpianisten und Arztes Herrn Wolfgang Ellenberger gestalteten sie zur feierlichen Übergabe der Diplome an die frisch gebackenen Diplomanten den musikalischen Rahmen.

AKUPUNKTURÄRZTE-ORCHESTER |Den Impuls von Timmendorf 2018 wollen wir nutzen, um im Jahr 2019 mit Ihrem musikalischen Talent das „Deutsche Akupunkturärzte-Orchester“ zu gründen. Unser Kollege Herr Wolfgang Ellenberger übernimmt die musikalische Leitung. Die aktuellen Anmeldungen sind vielversprechend und über unser Büro in München möglich. Die Proben finden am Samstag (07.09.19) und am Sonntag (08.09.19) im Kongresshotel statt. Dabei wollen wir bei der öffentlichen Aufführung am 10.09.2019 auf die schwierige Lage der Forschungsfinanzierung im Bereich der Akupunktur aufmerksam machen. Außerdem werden zwischen den Musikstücken kurzeVorträge für Patienten mit interessanten Informationen zum Thema Akupunktur gehalten. Seien Sie mit dabei, wenn wir mit Musik Qi-Stagnation beseitigen und unsere Begeisterung für Akupunktur durch diese musikalische Form von Öffentlichkeitsarbeit zeigen.
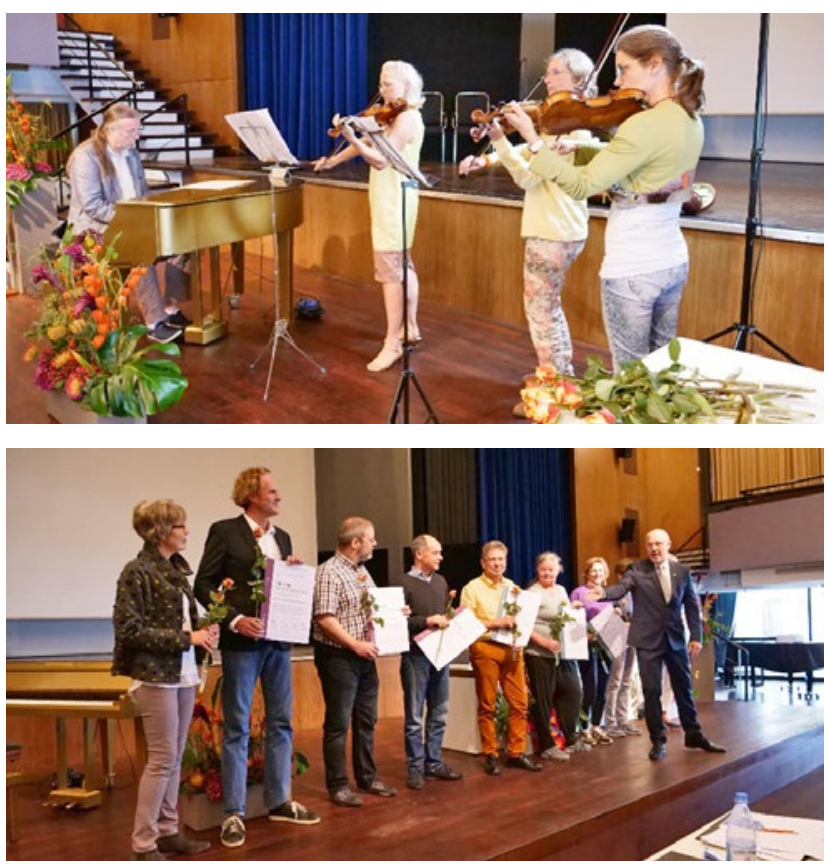

MITGLIEDERVERSAMMLUNG | Auf der Mitgliederversammlung am 10.11.2018 in Berlin wurde derVorstand bestehend aus dem 1.Vorsitzenden Dr. Bernd Ramme, dem 2.Vorsitzenden Human Dr. Arnfried Reis und dem 2.Vorsitzenden Zahn Dr. Hannes Rehfeld für weitere vier Jahre wiedergewählt. Im Namen des gesamten Vorstands bedanke ich mich für das uns entgegengebrachte Vertrauen.

HOMEPAGE RELAUNCH | Die Arbeiten bezüglich unserer Homepage schreiten planmäßig voran. Wir erwarten zu Ende Januar eine ersteVersion, die zur Referentenschulung am ersten Februarwochenende in Salzburg vorgestellt werden soll.

Ihr

B. Ramme

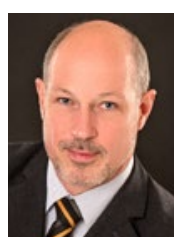

Dr. med. Bernd Ramme

1. Vorsitzender der DAA e.V.

Osserstraße 40, D-81679 München

Tel. $+4989 / 8145252$

E-Mail des allg.Büros: kontakt@akupunktur.de, Internet:www.akupunktur.de 